\title{
Study and Analysis of Various Violin Playing Schools
}

\author{
Rui Zhang ${ }^{1,}$, Hui Hui $\mathrm{Ji}^{2, \mathrm{~b}}$ \\ ${ }^{1}$ Institute of Art of Shandong University(Weihai), China \\ ${ }^{2}$ Institute of Art of Shandong University(Weihai), China \\ a705658299@qq.com
}

Keywords: Violin; Schools; Analysis

\begin{abstract}
The violin is one of the bowed string instruments. It was mainly used to be as a kind of music accompaniment for the dancers and songs, or a separate performance at the earliest. Later, violin playing also showed a variety of forms, more colorful, and different styles of violin performance art appeared with the changes of times and improvements of technology, which has also given rise to the emergence of various violin playing schools, there are primarily the Italian, French, Russian, German and other Schools created in the violin playing field. This paper focuses on the analyzes and research of these 4 different Schools of violin playing in order to facilitate the future development of the violin playing art and provide some useful help to the players.
\end{abstract}

\section{Introduction}

The violin was firstly very popular in Italy, since the Italian people prefer the musical instrument Violin, the Italian school of violin playing has formed after a long development. But learners in other countries have conducted some adjustments and improvements so as to form their own schools. So, the performance art style of each school is different, and it has continuously changed with the gradual changes of times. The following is a detailed analysis and research on the 4 different violin playing schools.

\section{The Italian School}

The Italian violin school is the earliest origin and development of the violin. It was formed in the Italian's folk violin playing, and had gradually formed its own style of playing. The Italian school, the earliest created school in the world, hadconstructed a solid foundation for the future development of the violin playing art. The founders of the school mainly included persons such as Vivaldi, Tartini and Paganini. In the 17th century,Corelli, an Italian, the most famous violinist who was known as the "king of the musicians.", was not only an important founder of the violin, but also was the world's first professional violinist, who played a very important role in the development of the violin. At that time, their creation and performance could be seen to be remarkably true to life, they couldeven imitate the cry of cats and barking of dogs by violins with a variety of tips on violin playing, which had made a tremendous impact on the society at the time and a lot of performers started to imitate theirs [1]. Then later, Corelli began to organize and edit some of the clutter data left by predecessors, so some relatively regular violin playing theories were formed by him.

Paganini was considered as the most influential player among the Italian school. He started to learn the violin playing when he was a child, and he became a player from his age of 13, he had 
been to the major cities of Europe throughouthis lifetime. till the 18th century, the traditional violin playing style had been unable to meet the needs of society at that time with the development and change of the era, people were eager to see acompletely new style of violin playing. Paganini, whowas affected by the trend of development at that time, created his passionate violin playing style to fully show his performances that was playing the violin with much more ideological enthusiasm and freely thinking. His kind of performance was to an extremelyhigh extent promoted well at that time, so he had became the "king of the violin."

Since then, many well-known performing artists has emerged among the Italy school, we can seefrom the whole development the virtuosos of the Italian school has showed us the singing of the violin by the use of wide and stretching bowings of the violinand displayed us the tips of the violin playing, it is the important reason why the Italian school is replaced by the thoughts and feelings school. However, the Italian schoolstill has played an important and indelible role in the development of the violin.

\section{The French School}

When the Italian school developed gradually in a decline trend, the French school was born slowly and quietly, and increasingly became active at the time of societies. In 1795, Paris Conservatory was formally established on behalf of the normalization of the French musical art and a formal teaching was formed. Leo Claire and Viottibroughtthe best things of the Italian school into France, and combined it with local culture and art forms so that the initial prototype of the French School was created [2].Those famous representatives of the French school are Viotti, Kreutzer and Bayeux, etc.. Viotti, an Italian famous violinist, combined the outstanding skills of the Italian school and the performance skills of the French school due to his prolonged life in Paris. he was also the founder of the French school. His playing mainly showed us a noble momentum and passionate enthusiasm, the performance usually make people feel excited with enough enthusiasm.Kreutzer is a French violinist, a professor at the Paris Conservatory of Music with own certain insight in the professional domain. And affected by Viotti, his performance wasnot only more beautiful, but also it included certain characteristics of the times. Bayeux is a famous French violinist and also a professor at the Paris Conservatory, his instrumental performance showed us prominently the power of the sound and made us feel the vigorous and the honest. Chrysler is one of outstanding representatives of the French school in the 19th century in a title of"king of modern violin". He was born with good musical abilityand was admitted to the Vienna Academy of Music at 7 years old.He integrated by a further creation the essence of the French School into his violin playing of some unique style [3]. His playingsoundsplump, plentiful and delicate with a much more delicate handle of the details, shows his view of aestheticism. His playing style currently can be seen as a kind of unique and typical performance.

\section{The German School}

The German School also includes the Hungarian school, the style of the German school often varied becausethe development of the German school was influenced by the Italy school in the early stage and the French schoollater. It can be said that the German School formedits own style finally based on the characteristics of the nation's culture and influenced by a variety of different styles.Joachim is a Hungarian violinist. His musical performance seems more rigorous, an art of tension and rustic, it can really show the connotation of the works of art and pay more attention to the emotional expression of the work.He thinks thatthe works of art of a violin musician must involve more things, 
it is necessary to study many different art styles, and infuse own emotion into the performance so that to create own unique art style. Xgetty is also a famousrepresentative of German school in the middle of the twentieth Century[4]. He entered the Royal College of Music in Budapest by the influence of his father in his childhood and was educated by Joachim. At the age of 13, he started to perform publicly in the school, which laid a solid foundation for his future career development. He absorbedthe influence of many different violin playing styles and gradually he formed his own unique view with more clear direction. A lot of excellent works are displayed for the people by his superb skills, which has made a great contribution to the development of the violin.

\section{The Russian School}

The Russian school was affected by the impact of the above described 3 different schools before its coming into being, at that time, a lot of artists from Italy, France and Germany went to Russia for performanceswhich had provided a foundation for the formation of the Russian school. The representatives of the Russian school mainly includes Elman, Heifetz, etc.. Elmanis an American violinist, one of the important persons contributed to the formation of the Russian school [5]. He began to learn violin playing since his childhood, he could play the violin well when he was 6 years old, and he was discovered by the violinist Orr who heard his performance and thought he was a genius, and thus was brought to the St. Petersburg Conservatory andtaught by Orr in person. His performance is mainly of grand and magnificent, including very rich and full mood. Heifetz is the most far-reachingviolinist of the Russian school in the 20th century. His performance is not only loud of the sound, expressive but also of superb skills which is able to show boththe noble and magnificent of the romanticist, but also the modesty and rigorous of the classicism. We can feel that his performance has always been unique, and can be faithful to the original work without exaggerated expressions.

\section{Conclusion}

The generation of the 4 major violin playing schools is inevitable by the social development and changes of the times. The creation of each art style indicates the progress of the society and history, but the disappearance of certain type of the violin playing schoolsdoes not mean the extinct of the traditional art forms but another new form of its rebirth.

\section{Reference List:}

[1] Analysis of the Violin Playing Schools (In Chinese) [J]. Northern music, 2016, (02): 41-45, J. Zeng.

[2] Thoughts about the Adult Violin Teaching Practice in Normal Colleges (In Chinese) [J] Northern music, 2016, (02): 60-63, M.Wu.

[3] Discussion on the Formation of Various Violin Playing Schools (In Chinese) [J] Popular Literature, 2015, (23): 77-79, H.J.Jiao.

[4] Research on the Situation and Strategies of Violin Teaching in Colleges (In Chinese) [J] drama House, 2015, (09): 60-65, P.Huang.

[5] Discussion on the left hand playing tips in the violin performances (In Chinese) [J] Science and Technology Outlook, 2015, (19): 20-24., H.N.Bi. 